\title{
Covid-19 and Asian Criminology: Uncertainty, Complexity, and the Responsibility of $A J O C$ Amidst Eventful Times
}

\author{
Jianhong Liu ${ }^{1} \cdot$ Yan Zhang ${ }^{2} \cdot$ Xiaoxiang Wang $^{3}$ \\ Published online: 1 March 2021 \\ (c) The Author(s), under exclusive licence to Springer Nature B.V. part of Springer Nature 2021
}

The 2020 Covid-19 pandemic is unquestionably one of the most influential worldwide events to occur in recent history. As of January 2021, the global infections surpassed 100 million, and more than 2 million lives were killed by the virus (WHO 2021). The magnitude of the pandemic - the shutdowns and disruptions permeating individuals' everyday life, institutional routines, and global governance-is calling for social scientists worldwide to think deeply about basic questions of social order and social change. Likewise, Asian criminologists are no exception. The AJOC has always been committed to advancing the study of criminology and criminal justice in Asian contexts (Liu 2009). Now, it is high time to keep that commitment and contribute an Asian understanding of the consequences of the pandemic in criminology and criminal justice. Therefore, we organized this Covid19 special issue.

Covid-19 can be seen as the largest criminological experiment in history (Stickle and Felson 2020). Relevant studies are exponentially growing, an overwhelming majority of which has focused on the crime rates during the pandemic. Initial evidence shows that conventional crimes such as residential burglary declined due to the social distancing measures and lockdown policy which increased guardianship over personal property and space (e.g., see Boman and Gallupe 2020; Felson et al. 2020; Miyar et al. 2020; Mohler et al. 2020). In contrast, the stay-at-home orders in the pandemic might create a worst-case scenario for individuals suffering from domestic violence (DV) as cases and arrests related to DV increased during the period (e.g., see Boserup et al. 2020; Bradbury-Jones and Isham 2020; Mohler et al. 2020; Piquero et al. 2020). A few research paid special attention to the potential impacts of pandemic policing on police legitimacy (Grace 2020; White and Fradella 2020). Overall, the existing studies are concentrating on western societies.

Jianhong Liu

jliu@um.edu.mo

Yan Zhang

ian.zhang@anu.edu.au

Xiaoxiang Wang

xiaoxiang.427@163.com

1 Faculty of Law, University of Macau, Taipa, Macau, China

2 School of Regulation and Global Governance (RegNet), Australian National University, Canberra, Australia

3 Chinese Academy of Social Sciences, Beijing, China 
How the pandemic has affected crimes and criminology in Asian contexts remains largely unexplored.

The core remit of this special issue is to explore both the general and special criminological questions emerging in the pandemic crisis and how they can be answered in Asian contexts. In doing so, we outline four critical questions, among which the first one is more general and the latter three are specifically targeting the emerging issues caused by the pandemic:

1) How does the Covid-19 pandemic impact crime patterns and victimization?

2) How does the Covid-19 pandemic heighten discrimination against vulnerable groups, particularly when the spread and control of the virus were highly politicized?

3) How do Asian countries such as China respond to Covid-19 differently compared to their western counterparts?

4) How does the Covid-19 impact the operation of the criminal justice system?

Due to the limited space available for each issue, it is impossible to consider every country in Asia, especially considering its geographical diversity. While the issue only covers three countries, the two most significant countries have been included: China and India. The former is where Covid-19 first gained world attention and prominence. The latter is the home of the second-largest number of infections in the world thus far. The total population of these two countries occupies $37 \%$ of the global population, and $61 \%$ of Asia's.

Overall, the Covid-19 special issue of AJOC has ensured fairly full consideration of the geographic diversity and the variety of topics which could ultimately convey insights into the complexity and the uncertainty that Covid-19 brought to Asia and to Asian criminology. In the following section, we will briefly introduce the six articles, which have respectively addressed each of the four questions raised, with a special strength: how they are answered in Asian contexts.

In the first article, Impact of COVID-19 on selected criminal activities in Dhaka, Bangladesh, the author outlines the early impact of the COVID-19 lockdown on selected crimes in Dhaka, Bangladesh. Relying on data of the total number of arrests, the article applies an uninterrupted historical time series analysis to evaluate the immediate impact during and after the official stay-at-home order. The findings suggest that the observed numbers of total arrests for vehicle thefts and illegal arms dealing were not significantly different from the predicted values. However, illegal drug trafficking showed a steep upward trend, which increased by $75 \%$ during the lockdown. The article reveals the relationships between Covid-19 and crime trends in emerging economies like Bangladesh. The results are also insightful for governments to take cautious measures in response to crimes in the eventful time.

The second article, Understanding Domestic Violence in India during COVID-19: A Routine Activity Approach, as shown by the title, applied routine activity theory (RAT) to explain the increasing prevalence of domestic violence during the pandemic in India. The authors revealed that alcohol and unemployment were the sources of motivation in likely perpetrators of domestic violence during the lockdown. The symbolic value placed on women by perpetrators and their lower inertia, visibility, and accessibility to the perpetrators were also strong indicators of suitable targets. Finally, a lack of police force and travel restrictions due to the lockdown contributed to an absence of capable guardians. The article shed light on regulating domestic violence, particularly during the Covid-19 period. 
The misinformation, disinformation, and fake news that spread along with the outbreak of Covid-19 have exacerbated the vulnerabilities of individuals who have already suffered during the pandemic. The third paper, We Are All Victims: Questionable Content and Collective Victimisation in the Digital Age, timely investigates this scenario. Drawing on recent examples from India, Chang and his co-authors examined and analyzed the rationale and modus operandi-both methods and types - that lead us to regard questionable content as a new form of collective victimization. The article pays particular attention to the questionable digital content regarding Covid-19, targeting different political parties and religious groups in India, which were illustrative of the power of misinformation and fake news, and the resultant damages to individuals and societal harmony. The authors also argue that it is necessary to acknowledge that individuals are collectively victimized by questionable content before we can successfully implement effective regulation.

The fourth article, Stigma, Discrimination, and Hate Crimes in Chinese-Speaking World amid Covid-19 Pandemic, addresses the issue of stigma and targeted hostility by exploring their origin, development, and impact on the Chinese-speaking populations both in China and globally during the pandemic. By using data from interviews with victims, online observations, as well as the data mining of media reports, the authors found that during the initial stages of the Covid-19 outbreak, stigma was inflicted by the non-Hubei Chinese population onto residents of Wuhan and Hubei; by some Hong Kong and Taiwan residents onto mainland Chinese; and by some Westerners onto overseas Chinese. The article further points out that factors including fear of the disease, food and mask culture, political ideology, and racism have affected the stigmatization of different victim groups. With its rich and triangulated data, this article is also a vivid depiction of how individuals have suffered from the hostility, bias, and hatred bred amidst the pandemic.

Semiformal Organizations and Control During the COVID-19 Crisis in China probes how formal organizations, semi-formal organizations, and informal groups all participated in regulating the pandemic and social order during the outbreak in China. Based on the severity of the pandemic in China, the research team collected survey data in three different regions: (1) Wuhan, the capital of Hubei Province; (2) Hubei excluding Wuhan; and (3) 30 other Chinese provinces. This study found that semi-formal organizations had the highest level of participation in control and service amidst Covid-19. It also found that education and age were the two major predictors of Chinese citizens' perception of the importance of the three control mechanisms. This article makes a contribution to our understanding of the relative importance of each form of social control and service in China. These insights might be applicable, to some extent, to western counterparts in their battle with the pandemic.

In the last article, Administrative Governance and Frontline Officers in the Chinese Prison System During the COVID-19 Pandemic, the author unveils rare, unique, and timely insights into prison officers' work in carceral institutions in China, a country where access to such institutions for researchers is highly restricted. Using first-hand and second-hand data, the author explores the execution of control policies in prisons during the pandemic, and how prison officers' lives were affected. This study highlights that the maximum control and absolute lockdown of the whole prison site is effective in preventing the further spread of the virus behind the prison walls. However, these coercive measures neglected the needs of front-line staff and failed to acknowledge the personal sacrifices demanded and made in this process. Overall, this research not only enriches our understanding of the Chinese model of prison governance but also uncovers the Chinese government's rationale behind its pandemic control and regulation, which is still inundated with uncertainties, critiques, and conspiracies. 
The Covid-19 pandemic is one of the unprecedented events, reshaping our culture, governance, economics, politics, crime, and social interactions. Its uncertainty and complexity will continue to ripple through the calendar of 2021 and into the foreseeable future. The AJOC itself has also been disrupted in this eventful time. During the expansion of Covid-19, many researchers had difficulty in meeting the timelines associated with our peer-review processes. We sorrowfully read the obituary of one acquaintance who contributed his review work to the journal before. He died as a result of the virus. One of our editors, of Chinese ethnicity living in Australia, always hesitated before wearing a mask when going out for grocery shopping. Though he had good knowledge of conceptualizing shame and stigmatization, he still needed a great deal of self-adaption to absorb the finger-pointing and sometimes even cursing for the "China Virus" from white locals in the supermarket (exactly like what the stigmatization article revealed). AJOC itself inevitably has become a part of the pandemic's footnotes. By publishing this issue, we hope to stay true to the commitments and responsibilities of AJOC. We hope that $A J O C$ can provide a forum for a shared project for us as criminologists, along with other rigorous and innovative scholarship across a range of disciplines, to advance our understanding of the nature, character, and consequences of the global crisis.

\section{References}

Boman, J.H., \& Gallupe, O. (2020). Has COVID-19 changed crime? Crime rates in the United States during the pandemic. American Journal of Criminal Justice, 45(4), 537-545. https://doi.org/10.1007/s1210 3-020-09551-3.

Boserup, B., McKenney, M., \& Elkbuli, A. (2020). Alarming trends in US domestic violence during the COVID-19 pandemic. American Journal of Emergency Medicine, 91(20) 3-5. https://doi.org/10.1016/j. ajem.2020.04.077.

Bradbury-Jones, C., \& Isham, L. (2020). The pandemic paradox: the consequences of COVID-19 on domestic violence. Journal of Clinical Nursing, 29(13-14), 2047-2049. https://doi.org/10.1111/jocn.15296.

Felson, M., Jiang, S., \& Xu, Y. (2020). Routine activity effects of the Covid-19 pandemic on burglary in Detroit, March 2020. Crime Science, 9(1), 1-7. https://doi.org/10.1186/s40163-020-00120-x.

Grace, S. (2020). Policing social distancing: gaining and maintaining compliance in the age of coronavirus. Policing: A Journal of Policy and Practice, 1-20. https://doi.org/10.1093/police/paaa029.

Liu, J. (2009). Asian criminology - challenges, opportunities, and directions. Asian Journal of Criminology, 4(1), 1-9. https://doi.org/10.1007/s11417-009-9066-7.

Miyar, J.R.B.la, Hoehn-Velasco, L., \& Silverio-Murillo, A. (2020). Druglords don't stay at home: COVID19 pandemic and crime patterns in Mexico City. Journal of Criminal Justice. https://doi.org/10.1016/j. jcrimjus.2020.101745.

Mohler, G., Bertozzi, A.L., Carter, J., Short, M.B., Sledge, D., Tita, G.E., Uchida, C.D., \& Brantingham, P.J. (2020). Impact of social distancing during COVID-19 pandemic on crime in Los Angeles and Indianapolis. Journal of Criminal Justice. https://doi.org/10.1016/j.jcrimjus.2020.101692.

Piquero, A.R., Riddell, J.R., Bishopp, S.A., Narvey, C., Reid, J.A., \& Leeper Piquero, N. (2020). Staying home, staying safe? A short-term analysis of COVID19 on Dallas domestic violence. American Journal of Criminal Justice, 45(4), 601-635.

Stickle, B., \& Felson, M. (2020). Crime rates in a pandemic: the largest criminological experiment in history. American Journal of Criminal Justice, 45(4), 525-536. https://doi.org/10.1007/s12103-02009546-0.

White, M.D., \& Fradella, H.F. (2020). Policing a pandemic: stay-at-home orders and what they mean for the police. American Journal of Criminal Justice, 1-16. https://doi.org/10.1007/s12103-020-09538-0.

WHO (2021). WHO coronavirus disease (COVID-19) dashboard. https://www.who.int/. Accessed 25 Jan 2021.

Publisher's Note Springer Nature remains neutral with regard to jurisdictional claims in published maps and institutional affiliations. 